\title{
Nonscientific University Students Training in General Science Using an Active-Learning Merged Pedagogy: Gamification in a Flipped Classroom
}

\author{
Francisco Zamora-Polo ${ }^{1,2, * \mathbb{C}}$, Mario Corrales-Serrano ${ }^{3}{ }^{\mathbb{C}}$, Jesús Sánchez-Martín ${ }^{3} \mathbb{D}$ and \\ Luis Espejo-Antúnez ${ }^{4}$ (D) \\ 1 Departamento de Ingeniería del Diseño, Escuela Politécnica Superior, Universidad de Sevilla, \\ 41011 Sevilla, Spain \\ 2 Departamento de Ingeniería Mecánica, Energética y de los Materiales, Universidad de Extremadura, \\ 06006 Badajoz, Spain \\ 3 Departamento de Didáctica de las Ciencias Experimentales y las Matemáticas, Facultad de Educación, \\ Universidad de Extremadura, 06006 Badajoz, Spain; mcorraletj@alumnos.unex.es (M.C.-S.); \\ jsanmar@unex.es (J.S.-M.) \\ 4 Departamento de Terapeútica Médico-Quirúrgica, Facultad de Medicina, Universidad de Extremadura, \\ 06006 Badajoz, Spain; luisea@unex.es \\ * Correspondence: fzpolo@us.es
}

Received: 30 October 2019; Accepted: 9 December 2019; Published: 13 December 2019

\begin{abstract}
Innovative teaching strategies are designing a new and promising landscape in education. They fill lessons with creativity and imagination for either the students or teachers. This article addresses an attempt to make the approach to science easier in a nonscientific environment: primary education at university level. Gamification methodologies were combined with a flipped classroom in order to free up in-class time and engage the students with the taught courses. A qualitative study was merged with quantitative measures of emotional and motivational parameters. These results were improved with four semistructured interviews. The results clearly showed a rise in the students' motivational levels, an acknowledgment of good teaching practices, and an evident enhancement of felt positive emotions toward science teaching and scientific issues.
\end{abstract}

Keywords: gamification; science education; technology education; flipped classroom; active learning methods; higher education

\section{Introduction}

The need for integral education in and outside school is a clear claim at present. In this context, academic aspects and others, such as civic education for a responsible citizenship, should be considered [1-3]. Educators (at any level) should take education into account as a whole-comprehensive process, where individual courses, such as mathematics, literature or plastic arts, should no longer be unlinked containers but pieces of a single puzzle. There are some aspects, such as motivation, emotions, and affective domain, which have not been adequately addressed in education in the past [4].

Innovative methodologies are a trending topic within education spheres. Methodologies like flipped classrooms, problem-based learning, design thinking or gamification are widely spread, and many scholars are working on them, either at primary school level [5], high school [6] or higher education $[7,8]$. Despite the relative novelty of such initiatives, all of them obviously respond to a very old question that has already been stated for a long time: How can we better engage more students in the education process, making it an excellent event? 
In order to obtain better results in terms of integral education, innovation within the educative general picture is urgent. Nevertheless, we agree with Yowel [9] when she claims that schools are not the place for testing new methodologies if they are not extremely well-controlled and monitored. In this sense, we think that higher education is an optimal lab to probe these new methodologies as, firstly, the students are more mature, and secondly, they will be able to apply these methodologies in their classrooms if they are effective. For these reasons, our study is focused on prospective primary teachers in a general science course.

\subsection{How Can We Teach Science to a Nonscientific Audience?}

If it is a challenge for educators to have knowledge about the most effective way of teaching, facing some specific issues can be even more complex. This is the case for Science, Technology, Engineering, and Mathematics (STEM) courses. It is commonly accepted that STEM courses usually cause negative emotions or emotions of disgust in those individuals that have experienced difficulty in their learning [10], and this is worrying because it evidences that a high percentage of bad emotional experiences is connected with a general rejection of science issues [11].The case of preservice primary teachers is even more relevant because their negative experiences can be shifted to their students, children that probably will receive the same negative messages about science and science education [12]. This creates a vicious circle: The student has a bad experience with the STEM courses in primary or secondary school, then they face negativity at university. Finally, they drive this experience to their students. Thus, the circle is closed.

The current trends in science education are aware of the importance of emotions, because there is no way of engaging students without taking their emotional performance into account. This is understood as the emotional response, positive or negative, experienced by a student when facing a particular course [13,14]. If this is relevant for teaching and learning any subject, it can be considered as a crucial aspect when teaching science, because science teachers usually begin with their students being in more difficult emotional positions [11].

There is, consequently, a search for good emotions in science teaching. It is also known that the loss of these good feelings toward science takes place during the instruction process: Children usually feel good when dealing with initial science issues (one just has to remember how they felt when the teacher brought a plastic yoghurt cup filled with cotton and a bean seed), but this feeling rapidly disappears as the years go on [15]. Gamification and the flipped classroom model are teaching methodologies that look to recover this initial surprise and good feeling amongst nonscientific university students.

\subsection{How to Overcome the Doing-the-Same Paradigm: Some Strategies and Considerations}

The basis of this work is our desire and need to make science easier, closer to the students' interests and clearer. Traditional methodologies, masterclasses, problem solving on the blackboard, and the use of questions and short answers without debate are poorly valued by students [16]. There are alternatives that really put the student in the center. Below, we describe two of them: gamification and the flipped classroom. The first one can create an optimal environment for the process of teaching and learning, whereas the second one enables extra free time for valuable activities for students. These two concomitant dimensions can easily build an active teaching method that probably enhances the students' emotional performance and motivation [14].

\subsubsection{Gamification}

There are many approaches to defining gamification. Generally, we agree with De-Marcos et al. when they state that: "Gamification is the use of game elements and game-design techniques in non-game contexts, to engage people and solve problems" [17] (p. 82).

It is remarkable that gamification, according to this definition, is not constricted to educational areas. Moreover, gamification seems to be born inside financial, marketing, and economical areas [18]. 
Educational gamification can add an external motivation factor in the learning process [19], as well as include a better emotional performance [16], mainly due to the fact that an alternative framework for the educational challenge is built on the basis of creativity behavior. Students should face the academic course not only as a job to do, but as a game to play, and a game must be fun [20]. Gamification connects directly with the student's interest center and generates a positive attitude towards the study task [18]. When asked about previous positive academic or instructional experiences, it is very common to obtain responses from students like: "That teacher was great, he/she taught us as if it was a game", "we learned as we were playing", or "his lessons were as if he was telling us a tale". The basis of gamification can be found even since the very early years of pedagogy and didactics, in a more or less explicit way. It is not a simple fortunate coincidence that Robert Fried named a central chapter of his main work as More Ways to Change the Game of School [21]. One can find suggestive statements such as: "It means helping them (the students) begin each course, each unit, and each class as players, not as spectators" [21] (p. 125).

\subsubsection{Flipped Classroom}

In a flipped classroom, the lecture is given outside the classroom, moving face-to-face time between the teacher and the students to activities which are different than a masterly lecture [22,23].

This methodology consists of more than putting the study materials in a space outside the physical classroom; it includes several elements that make the teaching process more efficient [24] (p.6). Some of them are the following:

1. When flipping a course, students are not simply asked to read and study alone, at home, some materials. You select the most appropriate materials for understanding the contents. Sometimes you generate them (video tutorials, podcasts, documents, etc.). For this purpose, you must choose attractive formats for the students-e.g., it makes no sense to ask students to watch a 45-minute video, when some studies have proposed that the novelty disappears within $10 \mathrm{~min}[25,26]$.

2. When students are able to understand the dynamics of preparing the classes before the lesson, it is possible to ask them to air their doubts and problems with the content prior to the face-to-face session, so as to be able to provide a just-in-time teaching experience [27]. This means adapting the exact teaching process and strategy to the current needs of the students.

3. One of the most struggled-with aspects of the flipped classroom is the fact that it implies a noncircular method for developing the content, so teachers are initially unable to check knowledge acquisition. This drawback can be overcome by implementing gamification measures (such as giving rewards) or forcing the students to participate in just-in-time teaching by asking questions or exposing what was not clear enough.

4. Once students are involved with this process, their participation with the course development increases highly, so, usually, the global academic marks are increased as well.

Figure 1 presents, in the form of a graph, the main differences between classical oral-based lessons and the flipped methodology. As can be appreciated, this strategy demands a higher level of students' involvement, but it allows generating a more creative and exciting learning environment at school. 


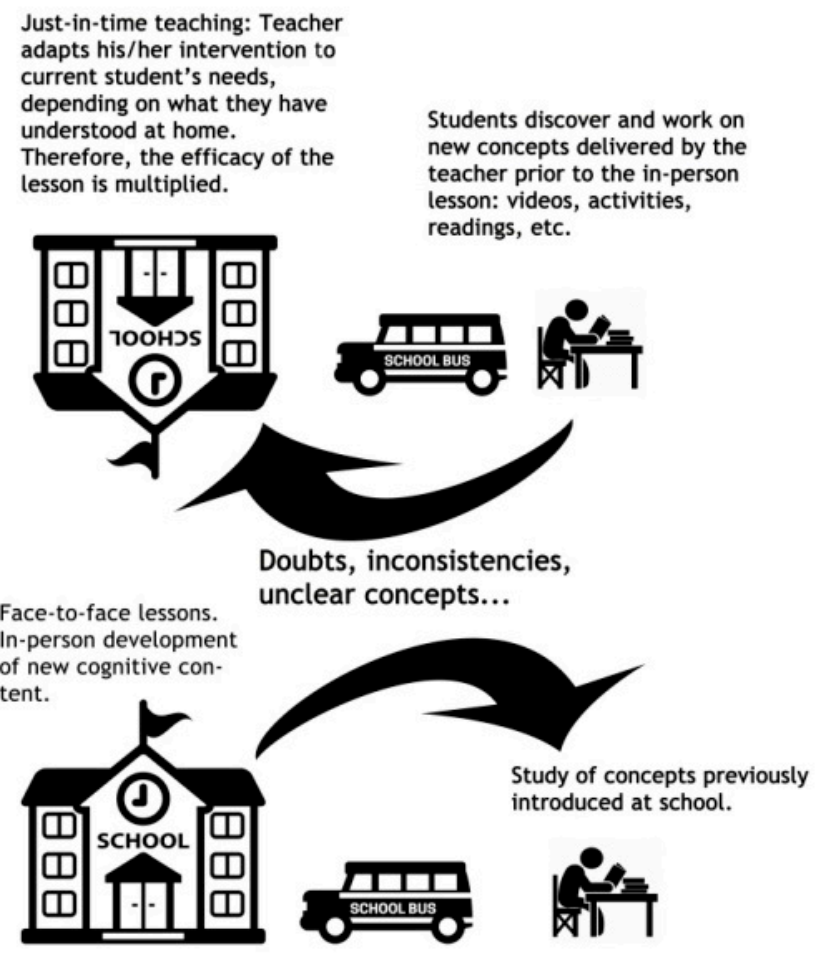

Figure 1. Flipped classroom model vs. traditional oral-based teaching model. Source: own elaboration from González-Gómez et al. [22]. Icon credits: Emoji One, CC BY-SA 4.0 and www.onlinewebfonts/icon CC BY 3.0.

\subsection{Objectives and Working Hypothesis}

In recent years, the use of gamification and the flipped classroom has increased substantially at different stages of education. However, the combination of both methods has not been fully analyzed. The main objective of this research is to study the combined use of gamification and the flipped classroom in science education and to determine whether their combined use could have a positive effect on the development of the teaching-learning process.

The specific objectives of the work are:

1. To describe an experience of combined use of gamification and the flipped classroom.

2. To analyze the opinion of the students about the organization of the course.

The hypotheses that we intend to test in the work are:

Hypothesis 1. The combined use of gamification and the flipped classroom has a motivating effect on the students.

Hypothesis 2. The emotions felt by the students are predominantly positive.

Hypothesis 3. The students consider that this methodology can be applied in the future in their classes.

\section{Methodology}

This research was carried out by merging several methodologies. Some of them are quantitative, measuring students' motivation level through surveys. In order to obtain more information, a qualitative study based on the interview of selected students was developed. Regarding ethical procedures, all participants provided informed consent and gave us consent to use their answers for our research with academic purposes. In order to maintain anonymity, all names used in the article are purely fictitious. 


\subsection{Instructional Design}

The flipped classroom materials consisted of a series of video tutorials (made ad hoc) focusing on the most relevant points of each chapter: Archimedes' Principle, solutions and concentrations, moles and Avogadro's number, and so on. Although YouTube ${ }^{\mathrm{TM}}$ videos were allocated at the teacher's own channel, some of them can be revised at https://www.youtube.com/watch? $\mathrm{v}=\mathrm{gk} 6 \mathrm{UdAZBnVs} \& \mathrm{t}=377 \mathrm{~s}$ or https://youtu.be/2GaB-HrLhDM (in Spanish). Additionally, some aspects were developed using written documents (no more than two pages each) or other external links. The main goal of the flipped classroom is to release part of the classroom time in order to use it to develop the most complex concepts (just-in-time teaching, as mentioned before). Hence, the time with the professor can be leveraged, and better academic results can be obtained. This methodology helps students to focus their attention on those relevant aspects that should be clearly understood.

The general gamification proposal is fully described elsewhere [18], with a narrative linked to Star Wars ${ }^{\mathrm{TM}}$. The course included 30 sessions $(90 \mathrm{~min})$ that were systematically organized in the following way:

- The first 20 min were focused on discussing and clarifying doubts that could arise during the flipped period (before the face-to-face lesson). This corresponds to just-in-time teaching.

- Then, the teacher developed new content in an oral-based methodology for no longer than $20 \mathrm{~min}$.

- The flipped and the classroom content were applied by doing some cooperative activity for at least $40 \mathrm{~min}$ (problems, little research, etc.)

- Finally, a game-based activity was implemented to generate good feelings.

As can be appreciated, the students got into the lessons with a high level of participation. Oral exposition was constricted to a minimum time within the $90 \mathrm{~min}$ of the classes. This was done in order to engage the students to attend the classes, as attendance is not mandatory at university.

Some game-based activities for playing inside the classroom were the following:

1. Classical board games such as Taboo ${ }^{\mathrm{TM}}$ or Time's up! ${ }^{\mathrm{TM}}$, where the themes have been changed to be linked to the course's contents. For example, with Time's up! ${ }^{\mathrm{TM}}$, the definitions must deal with the universe and students must play describing concepts such as Terminal Shock, Heliosphere, Comet or Big Crunch.

2. Other proposals included little tricks for forcing the students to read, understand, and study some concepts. This is the case of "Match and Find", where the presentation slides and the corresponding explanation in the comments were split off and students must put them together again.

3. An educative escape room experience, where students were confined in a classroom and several scientific and nonscientific challenges should be faced and solved to get out. Escape rooms were born in Japan [28], and their educational use is relatively new [29].

4. Competitive questionnaires on and offline: Kahoot $^{\mathrm{TM}}$, Socrative ${ }^{\mathrm{TM}}$, Quizziz ${ }^{\mathrm{TM}}$, and other proposals were performed sequentially to check out the knowledge acquisition.

5. Scientific coffee: Students were received at the classroom with a free coffee and a paper napkin at their seats. Then, a very difficult problem with its corresponding solution was given, a different one for each student. The purpose of this scientific coffee is to provoke a scientific talk (each student must explain their problem to the classmate sitting next to them) inside a relatively nonformal situation. The explanation, therefore, must be written down on the napkin.

6. Collaborative Problems Jigsaw: Several proposals of puzzles were given during the course. The entire problem was segmented into four or five parts that must be put together to face the problem. Each part was given to a different student's team, so their collaboration was absolutely needed for the success of the whole group. An example of such an activity is given in Figure 2. 


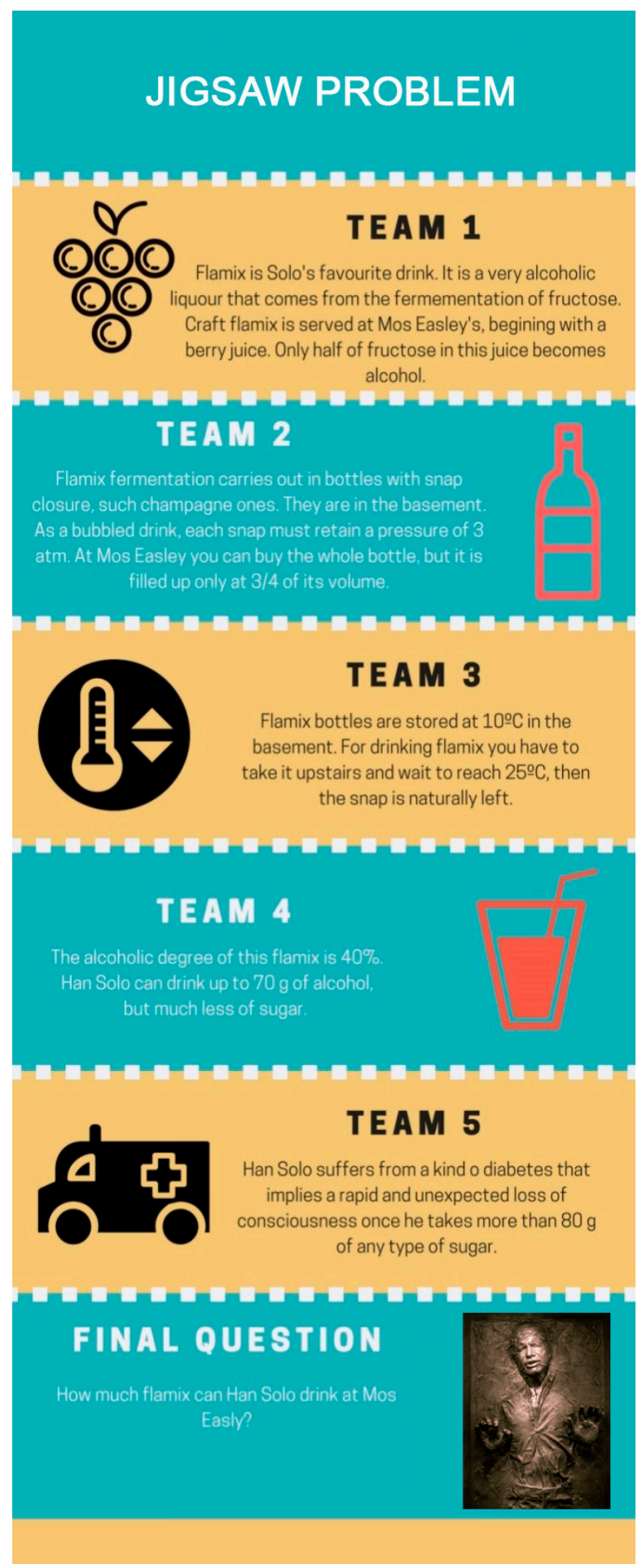

Figure 2. Jigsaw activity scheme. Each team has only one corresponding piece of the problem. Own elaboration with Canva ${ }^{\mathrm{TM}}$ for educational purposes from a redistributable-non authorship license.

A resource-based game structured the whole course, so students were able to obtain points that could be changed based on benefits and advantages at the final exam. To this end, although those points could be gained during the in-person lessons, a parallel game based on working in teams outside the class was proposed. In this methodology, difficult problems involving the scientific concepts taught in class were proposed to be solved (out of class). An example of such proposals is given in Figure 3. 


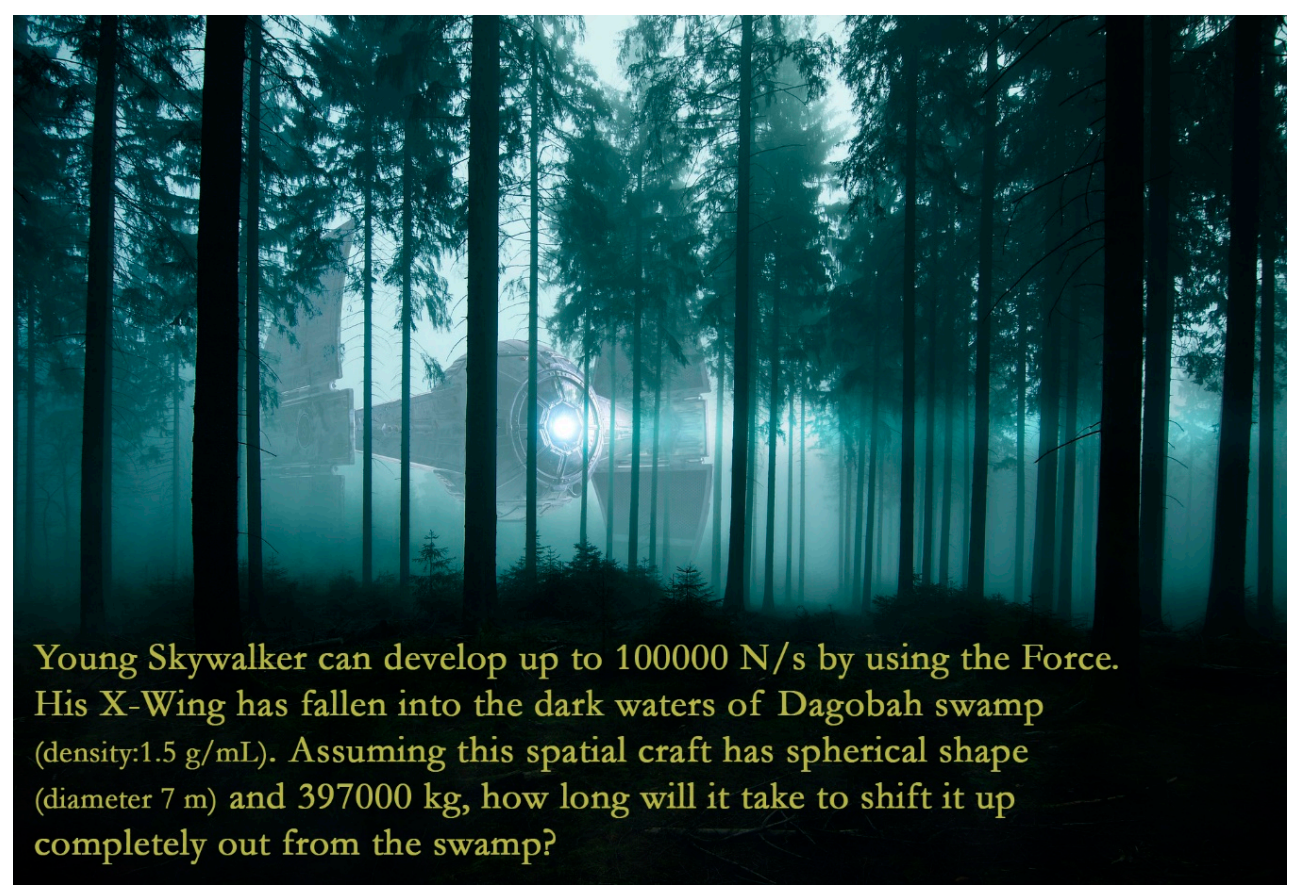

Figure 3. Presentation of a game-based problem for teaching Archimede's principle in gas fluids. Own elaboration for educational purposes from a redistributable-non authorship license.

\subsection{Sample Description}

The study sample consists of 18 students, 10 females and 8 males, aged between 19 and 25. Most of them are 19-20 years old, the corresponding age for studying this 2nd year of preservice primary teachers. They study in an Education Faculty (not Science one or similar), and this fact makes this sample relatively different from others. The students are part of group number 4 (afternoon time). Many of these students do not have very high academic marks except in the case of workers (students that combine academic life with a traditional job in the morning). In the current case, the involved students were not workers, so they presented the lowest academic marks in the whole course. Usually, the size of this group is smaller than those of the groups taught in the morning. The low number of students $(n=18)$ allowed introducing innovative actions. These actions, properly analyzed, can be replicated, with their corresponding adaptations, to larger groups.

The general profile of the standard student of this course deserves a specific description, based not only on quantitative data, but also and above all on personal and direct observation:

1. As Jeong et al. recently pointed out [30], the academic background of the students in this degree is mainly linked to social science or arts studies. Additionally, they do not identify the studies for becoming a primary teacher as a science discipline, and obviously, there is no need to have good knowledge of many scientific concepts to be a good primary teacher.

2. As a result of the previous item, traits traditionally linked to scientific education values-for example, curiosity, observation, surprise, and so forth-are not present by default in the sample students. Even more, the initial emotions toward science issues in this kind of students tend more toward rejection rather than personal interest [31].

3. The academic structure of the syllabus for a Primary Teacher degree includes a huge number of different courses, belonging to a large variety of academic fields (arts, literature, physical education, music, history, geography, science, and so on) This has a direct influence on the importance and relevance students give to each topic. We observe that science education, since it is not an interesting course for the students in this degree, is often placed in the last place in order of importance by students. 
4. As a result of these circumstances, science education courses are passed by students with relatively low academic marks [22].

\subsection{Questionnaires}

With the aim of analyzing the experience, several surveys were developed. Some of them were made in the classroom (written down) and others were web-supported (using Google Forms ${ }^{\mathrm{TM}}$ ).

These surveys can be summarized into the following categories:

1. General surveys on participation level, regarding the flipped classroom activities. These were questionnaires that must be filled out prior to the face-to-face lesson. In them, the teacher asked the students about their doubts and feelings on the course they were working on then. An example of this kind of survey is given in Table A1.

2. Motivational surveys (made before and after the educational escape room). This had the purpose of checking a motivational rise in the general studies for preservice teachers and for the current course (Didactics of Matter and Energy). In these surveys, students were simply asked to express their own level of motivation (1-10 scale) towards (a) any class from the degree, (b) this specific class of Didactics of Matter and Energy, and (c) the next class of this course.

3. Emotional performance and science vision survey. A final evaluation of the course, considering the active methodology (Table A2). This survey included some quantitative items about the perceived difficulty in the course itself and an evaluation of the active methodology. In addition, some questions were proposed for inquiring about the best and worst aspect in course development and about the way the student will remember the course, with both items as open-response questions.

\subsection{Semistructured Interviews}

In order to improve the study, the questionnaires were complemented with a qualitative instrument. This consisted of semistructured interviews with four selected students. The selection was made considering the combination of two variables: initial motivation toward science courses and initial basic scientific knowledge, so the four students presented the entire range of feasible combinations as presented in Table 1.

Table 1. Selected students for semistructured interviews.

\begin{tabular}{ccc}
\hline Student's Fictitious Name & Initial Motivation & Initial Science Knowledge \\
\hline Ana & High & Low \\
Roberto & Low & High \\
Marta & Low & Low \\
Blanca & High & High \\
\hline
\end{tabular}

The interviews were conducted through five main open questions (many others arose during the interview) that offered the opportunity to talk about the course itself, about teaching science, and about the method the teacher used during the semester. These initial questions were the following:

- How did you feel when the course had just started, at the beginning of the semester?

- Did you like science prior to studying it at university?

- What do you think about the method the teacher has followed with this course? Do you think it is different from those of the rest of the courses?

- Do you think this method motivates the student to study better? Why?

- Does the teaching method influence the way the content is received by the student? In which way?

As recommended by Patton [32] for this qualitative researching method, the interviews lasted $30 \mathrm{~min}$, and then they were transcribed. The analyzed data were based on these transcriptions. 


\section{Results and Discussion}

Data were processed using statistical software package SPSS v.14 for Windows [33]. Due to the number of involved individuals (18 students attending), the results are a descriptive data landscape. In addition, their study together with qualitative interviews gave a consistent response to the working hypothesis.

\subsection{Questionnaries Results}

\subsubsection{Follow-Up Surveys}

As described in the previous section, students were required to answer to a survey after the flipped classroom activities. Students were rewarded with game points or other advantages if the post-survey (one for each flipped session) was filled out. This led to almost $80 \%$ of the students who attended to the face-to-face lessons regularly filling out each survey, although not always the same people. Most students gave satisfactory feedback in these surveys, and this participation rate reported the level of students' involvement.

\subsubsection{Motivational Surveys}

Figure 4 presents the motivational rise expressed by the implementation of the educative escape room, as part of a general innovation program in the course. The results confirm that students are more motivated towards science classes after a gamified activity with a high level of participation and with hands-on and funny aspects. As can be clearly seen, the motivation level rises for the three categories, but especially for the next class of Didactics of Matter and Energy. This confirms that for this group of students, these kinds of activities enhance motivation for the general studies (the whole degree) and, above all, for the science course. These results are consistent with other experiences analyzing escape rooms $[29,34-36]$, and they seem to show the fulfillment of hypothesis 1 , which says that the use of gamification has a motivating effect on the students. Escape room activities have been used to increase motivation in different contexts, in a course of computer engineering [34], in teaching physics of fluid [29], with pharmacy students [36] and even with university professors [35]. In addition to it having a motivating character, its use improves the development of skills such as: teamwork, critical thinking, etc. These skills, known as soft skills or transversal skills are highly valued by the labor market and are essential for the exercise of critical and committed citizenship [8,37,38]. In this sense, in future work, we want to address the perception that students have in the development of competences with gamification activities.

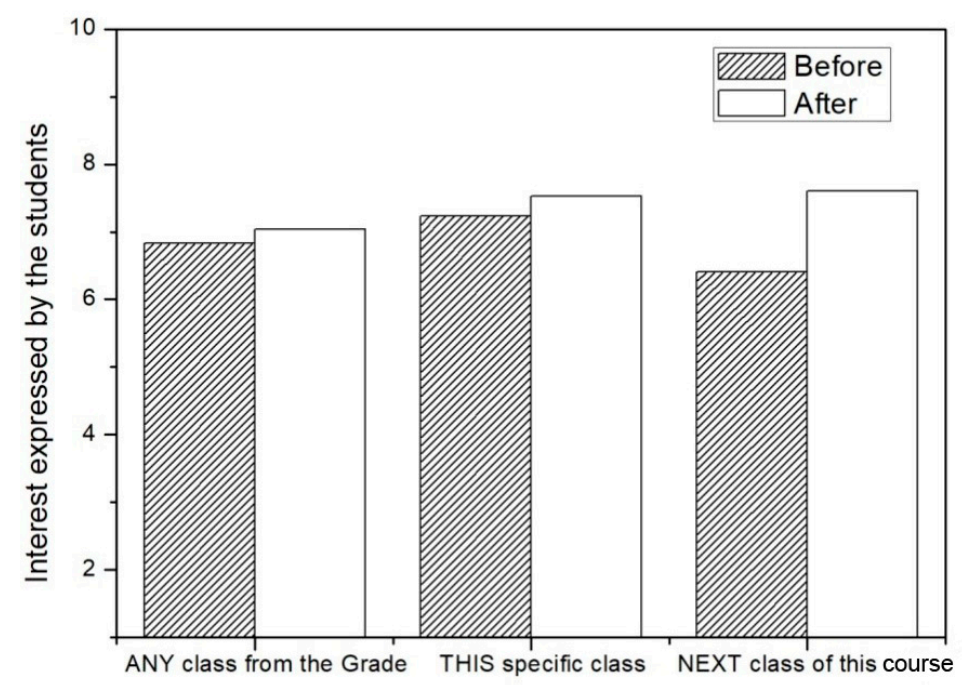

Figure 4. Motivational rise toward general classes in the degree and especially toward the course classes before and after the educational escape room activity. 


\subsubsection{Emotional Performance and Science Vision Survey}

Students were asked about the perceived difficulty of the course itself and the difficulty of the exam. A quantitative 0-10 scale was used. The course was considered difficult (an average consigned value of 7.61), as was the exam (an average value of 7.65). In addition, the responses were correlated and had a very high correlation factor $\left(\mathrm{r}^{2}\right.$ of 0.86$)$. This means the whole consideration of the course, including the final test evaluation, was in agreement with those preconceptions about science and science teaching that other authors already reported [10,12]. Graphically, these results can be seen in Figure 5.

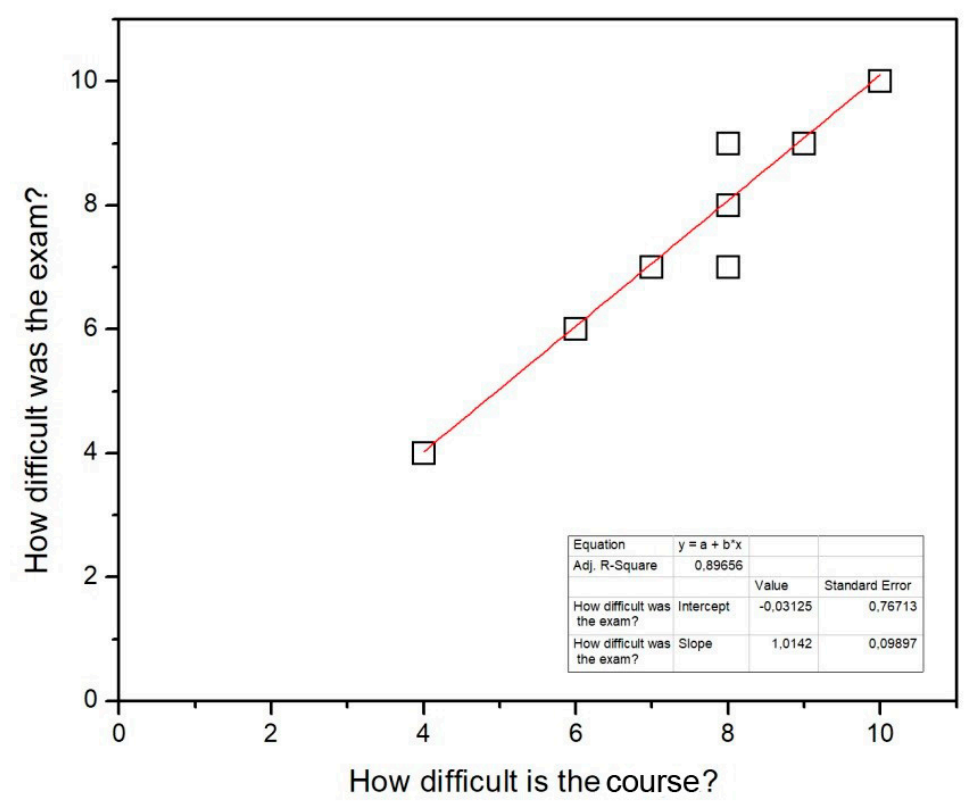

Figure 5. Correlation between the perceived difficulty in the course itself (Didactics of Matter and Energy) and in the final exam. Right lower case: statistics of the fitting correlation.

Although students did not experience the course or the exam as easy, they were asked about the teaching method afterwards (that is, once the course and the exam was over). The responses were again high enough to consider them as positive (average of 7.3). Figure 6 compares the two assessments (teaching method and course difficulty). In this figure, the response frequency to both questions is shown, although the axes are inverted to make the comparison easier. As it clearly depicts, students responded with a high similarity to both questions, and high rates are reached in them. There are only a couple of responses out of the 7-10 range. This means the students considered the teaching method as a good choice for science education, although we cannot distinguish whether they also consider these strategies advisable for prospective teachers.

As Section 2.3 presented, the last survey included two questions that should be answered with an open paragraph by each student. For this, they were asked to fill in the best and the worst aspect of the classes. Regarding the first question, almost everyone agreed in pointing out the methodology (gamification, applied science, innovative teaching method) as the best practice, whereas the worst aspect was the perceived difficulty of the course and the problem resolution.

Regarding the second question (How will you remember these classes?), the positive aspects of the teaching method were pointed out in a general way. Some examples of student responses are as follows:

'I will remember these classes as the best in the degree because of the methodology, but also as some of the most difficult ones.'

'Intense' 


\section{'A coffee with science'}

In general, the way the students expressed their ideas about the perception of the course shows that innovative methodologies improve the emotional performance of students, since they do not remove the difficulty that they detect in the science issues but make it more acceptable. This was also reported in similar studies, such as $[16,18,37]$.

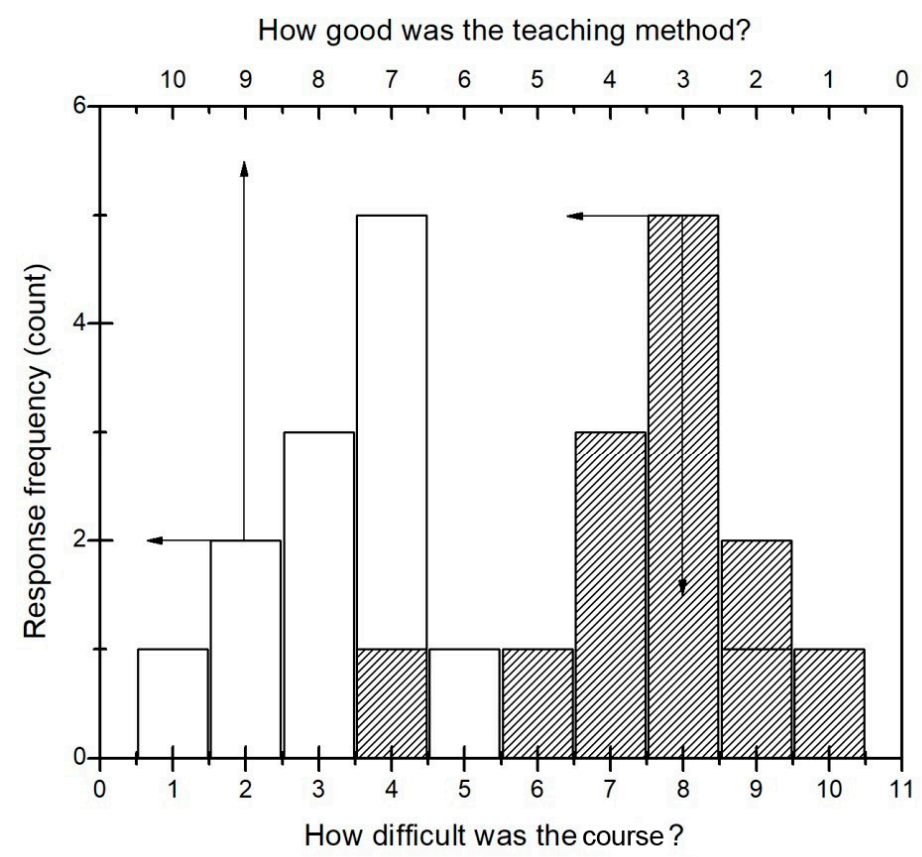

Figure 6. Response frequency to the questions about the course difficulty and the teaching method.

\subsection{The Semistructured Interviews}

The interviews were a great source of qualitative data. The first analysis of this material was made through data categorization. The transcriptions were coded to identify four data categories: student, emotional expression, kind of emotion (positive or negative), and reason for such a feeling. The descriptive results of the four interviews are presented in the following section.

\subsubsection{Descriptive Data}

At first, the frequency with which the students talked about their emotional experiences during the classes was analyzed. Expressions such as: "I feel confused when I faced the problem solving" or "From the first moment I felt curiosity. What was that called, 'gamification'?" were coded as emotional references. The first was coded as a negative feeling, and the second one as a positive emotion.

The total count for emotional references based on the different interviews is presented in Figure 7. Clearly, positive emotions are more frequent than negative ones (Figure 8). This is consistent with previously published works in the literature, for example, Bujacz et al. [39], who obtained a correlation of positive emotions with creative activities, or Suwal and Singh [40], who found mainly positive emotions in the use of the building information modeling (BIM) methodology using an online platform. Similarly, Jeong et al. proposed that active learning methodologies [41] and the flipped classroom cause positive emotions in students $[23,30,42]$ and enhance science self-efficacy in preservice teachers [43]. By contrast, Zamora et al. [8] found a plain emotional performance in a project-based learning activity developed using BIM in the university context. 


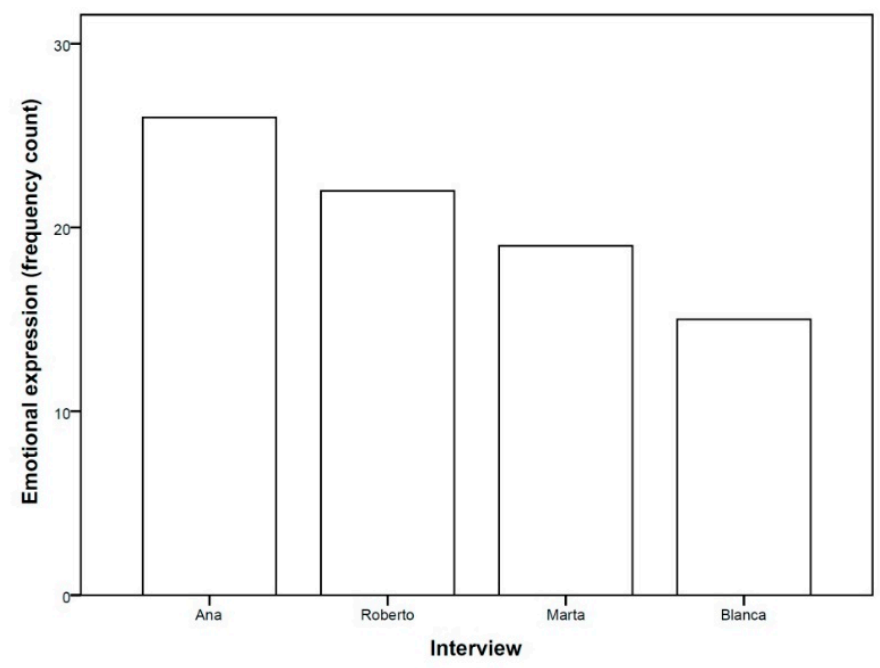

Figure 7. Responses frequency related to emotional references during the interviews.

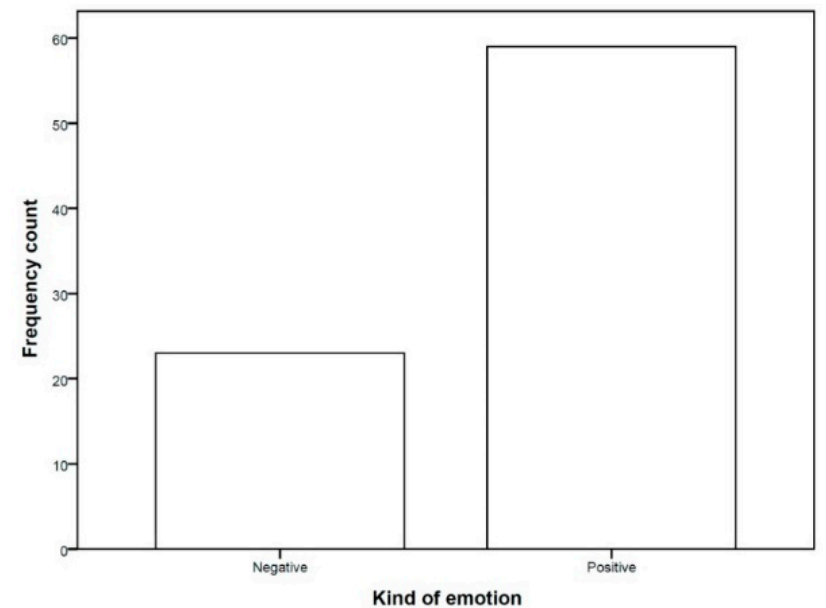

Figure 8. Kind of emotions (positive/negative) expressed by the students during the interviews.

In Figure 7, results are shown categorized by students. A clear trend in the data cannot be observed. The student who used more emotional expressions is the student with a high initial motivation and a low initial science knowledge (Ana); in the second place, a student with low initial motivation and a high initial science knowledge (Roberto) can be found. On the other hand, the student who used fewer emotional expressions is Blanca, a student who had initially a high motivation and science knowledge. These results seem to indicate that emotional outcomes depend more on the teaching-learning process than on the preconditions of the students.

Figure 9 shows the frequency account of different emotions. As can be seen from the graph, the three more positive emotions cited by students are motivation (22 times, $28 \%$ ), pleasure (12 times, $14.6 \%)$, and excitement ( 6 times, $7.3 \%)$; on the other hand, the three more negative emotions cited by students are fear ( 4 times, $5 \%$ ), confusion ( 4 times, $5 \%$ ), and anxiety ( 3 times, $3.7 \%$ ). As can be seen, the generated emotions are clearly positive; the number of times that motivation appears is more than 5 times greater than fear or confusion. This fact clearly confirms hypothesis 2 , which is that the methodology used enhances the students' emotional performance. These results are consistent with other studies than relate innovative methods with an increase in students' motivation [22,44]. 


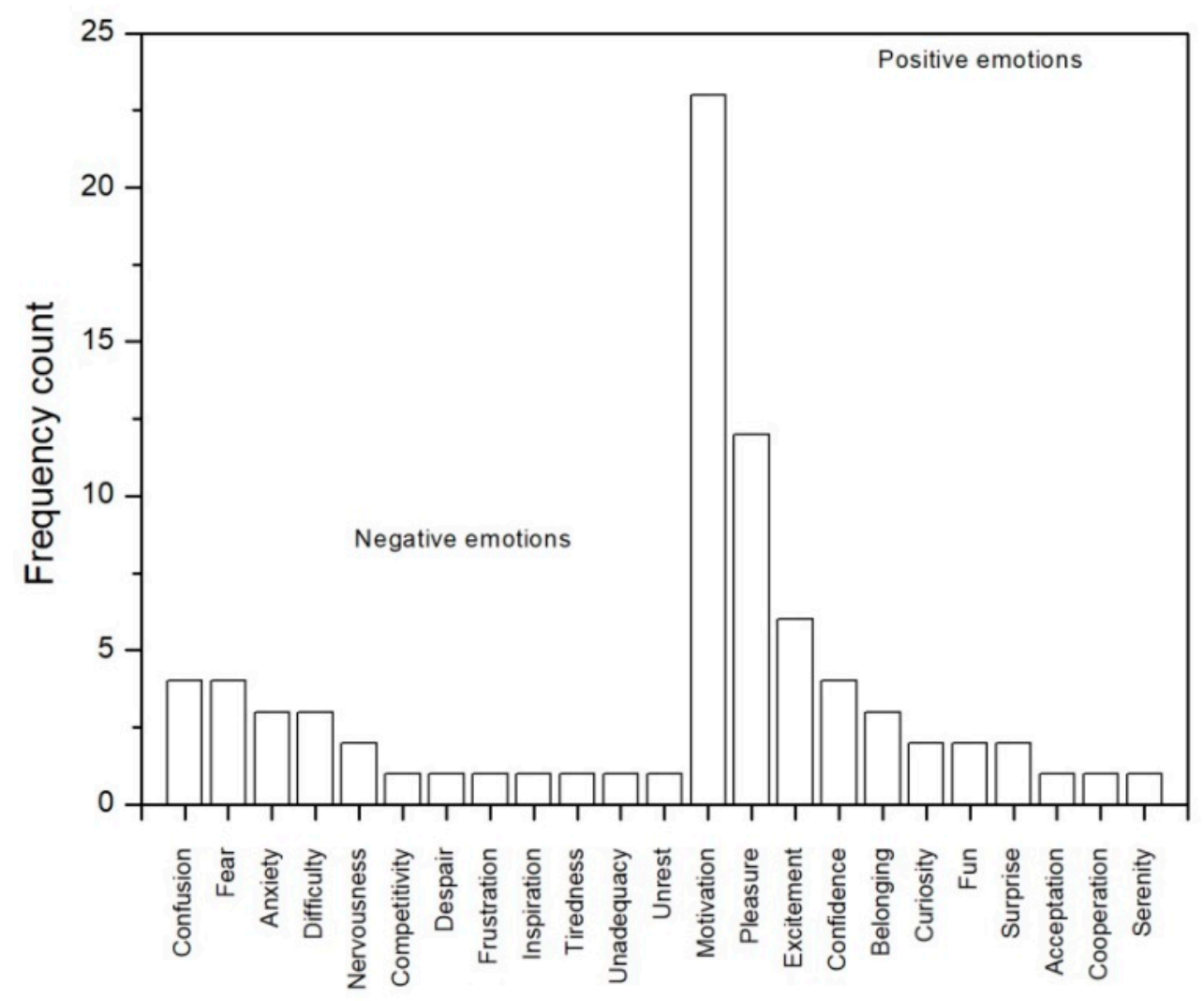

Figure 9. Emotions expressed by the students during the interviews.

Regarding the third hypothesis, two specific questions were asked in the interviews with the students: Do you think that what you have learned in class can help you in your professional future? Could you apply it to your classes?

Student number 1 (Ana) answered: "Yes, I think so, I would certainly like that. These methodologies are interesting and motivating. They make the classes easier, they are a good option."

Student number 2 (Roberto): "It depends on the students, for elementary school students I think it is a good option, the proposal should be designed and adapted for them; however, I would not apply these methodologies for adults."

Student number 3 (Marta): "Yes, I think so, yes. I really liked the games; cooperative learning is very interesting too. I think you can learn more from others than working alone."

Student number 4 (Blanca): "Of course! We have learned many methodologies. It is better to teach using an active methodology than using only theoretical classes. These contents should be introduced as soon as possible. Obviously, they should be tailored to students' age."

These answers show that students have acquired psychopedagogical skills alongside purely scientific skills. They have learned new methodologies, and they are willing to apply them in the future with their students. These results confirm hypothesis number 3; students develop new skills that will allow them to become better teachers in the future.

Finally, Figure 10 shows students' reasons related to their feelings. Throughout the interview, the students expressed the emotions they had felt in the subject and the reasons they had felt those emotions. The most frequent were methodology (49 times, 59.8\%) and current knowledge content (16 times, $19.5 \%$ ). It is quite remarkable the third position in the emotional frequency count corresponds to emotional expressions not linked to the academic event. That is, they arose in the interview not regarding academic aspects. 


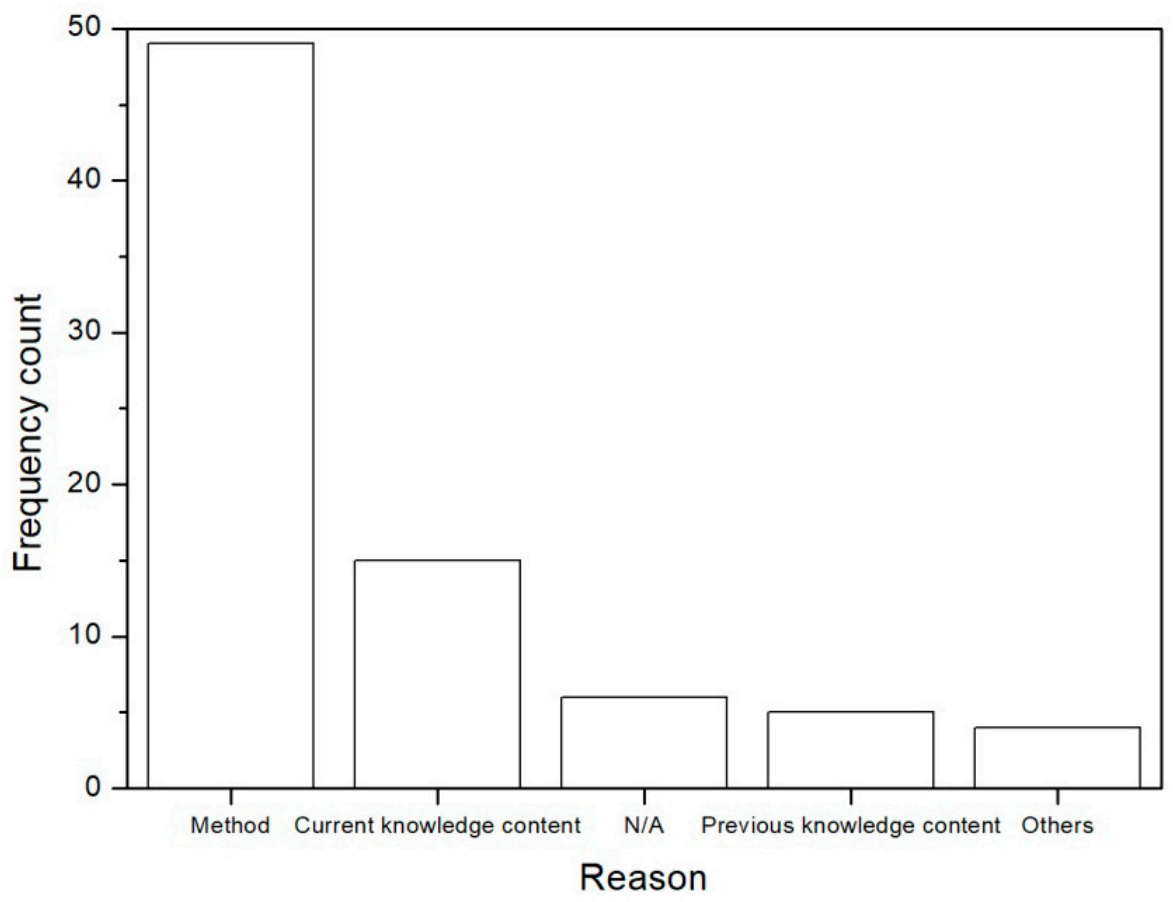

Figure 10. Reasons attributed by the students to their own feelings.

\subsubsection{Inferential analysis}

In order to get deeper into the analysis of the reasons for feeling one kind of emotion or another, that is, to clarify whether the negative emotions are linked to a specific reason and vice versa with the positive ones, an inferential analysis was carried out. This analysis is made based on a high number of emotional expressions (more than 50), although they are extracted from only four individuals. Therefore, the significance of such an analysis is constrained to this small experience.

The relevance of the emotional factor and affective domain has been discussed elsewhere [16]. To this end, we crossed the category Kind of emotion (which could be Positive or Negative) with the category Reason for feeling (which could be Current knowledge content, Previous knowledge content, Method, Not answered or Others). Table 2 shows the results of such crossing of data, according to an $\chi^{2}$ hypothesis test. As can be observed, $34 \%$ of negative emotions can be related with current knowledge content. On the other hand, positive emotions are associated with methodology in $73 \%$. This is statistically significant $(p$-value $=0.00)$, and a high value of contingency coefficient $(0.505)$ is reached.

Table 2. Inferential analysis of Reasons for emotions and Kind of felt emotions.

\begin{tabular}{cccccc}
\hline \multirow{2}{*}{ Kind of Emotions (K) } & \multicolumn{3}{c}{ Reasons } \\
\cline { 2 - 6 } & $\begin{array}{c}\text { Current Knowledge } \\
\text { Content }\end{array}$ & Method & Others & $\begin{array}{c}\text { Previous } \\
\text { Knowledge Content }\end{array}$ & N/A \\
\hline Negative (\% inside K) & $8(34.8 \%)$ & $6(26.1 \%)$ & $5(21.7 \%)$ & $4(17.5 \%)$ & $0(0 \%)$ \\
Positive (\% inside K) & $8(13.6 \%)$ & $43(72.9 \%)$ & $6(7.3 \%)$ & $5(6.1 \%)$ & $6(7.3 \%)$ \\
\hline
\end{tabular}

Secondly, the relationship between kind of emotion and student has been studied using the $\chi^{2}$ hypothesis test. There is no significant evidence to prove a relationship between the type of emotions and the student (1, 2, 3 or 4), surely because of the low number of individuals involved. This is consistent with the description of Figure 10 and could show there is no relationship between previous experience and emotions, and the new methodology causes positive emotions regardless of previous experience. 


\section{Conclusions}

In this study, we examined an educational innovation experience combining gamification and the flipped classroom. For the analysis of the experience, qualitative and quantitative techniques were used, using interview and surveys.

The following conclusions can be drawn from the results of the study:

1. Students still find science difficult. However, the use of innovative techniques improves their perception and motivation toward this discipline.

2. Students have learned new techniques that they can use in their future professional activity. This aspect means that the innovations developed in the university context have a multiplier effect because they can affect future generations.

Although the experience has been developed in a small group of students (18), the results show that it would be interesting to be able to apply it, with appropriate adaptations, in larger groups. In future studies, we will analyze the application of this technique in these groups.

Author Contributions: Conceptualization, F.Z.-P., J.S.-M. and L.E.-A.; methodology, F.Z.-P. and J.S.-M.; formal analysis, F.Z.-P. and J.S.-M.; investigation, F.Z.-P., J.S.-M. and L.E.-A.; data curation, F.Z.-P. and J.S.-M..; writing-original draft preparation, F.Z.-P., J.S.-M. and L.E.-A.; writing—review and editing, F.Z.-P., J.S.-M., M.C.-S. and L.E.-A; visualization, F.Z.-P., J.S.-M. and M.C.-S.; funding acquisition, J.S.-M.

Funding: This work was partially supported by the Spanish Government (Economy and Competitiveness Ministry) under EDU2016-77007-R (AEI/FEDER, UE) project, IB16068 (Junta de Extremadura/Fondo Europeo de Desarrollo) as well as by the Regional Government of Extremadura (GR18004) and by the Researching Group DEPROFE, from University of Extremadura.

Acknowledgments: Authors are most grateful to the students from Didactics of Matter and Energy (Group 4, Primary Teacher Degree) and especially to those four that actively participated as interviewed subjects and due to the anonymity cannot be mentioned. Authors thank M. Guerrero-González for her comments and suggestions on the preliminary versions of the manuscript.

Conflicts of Interest: The authors declare no conflict of interest.

\section{Appendix A}

Table A1. Preclass questionnaire (example).

\begin{tabular}{c} 
Preclass Questionnaire on Pure and Compound Substances \\
Name \\
Please give the name of three pure substances and explain the reason of such classification \\
Which aspect of the video tutorial was most clear for you? \\
Which concept or idea was not clear enough with the explanation? \\
Please evaluate the video-tutorial with a mark (0-10) \\
Finally, send me an urgent doubt (something you do not understand well) \\
\hline
\end{tabular}


Table A2. Final evaluation for the entire course. The survey was subtitled as follows: "This survey is only intended for improving my teaching practice. It is anonymous, voluntary, and will only be read by me. I would be grateful if you participate and be the sincerest and most reflective possible."

\begin{tabular}{|c|c|}
\hline Question & Scale \\
\hline Please evaluate the expositive classes (magistral lessons) & $1-10$ \\
\hline Any comment or suggestion for making them better? & Free text response \\
\hline Please evaluate flipped classes & $1-10$ \\
\hline What is the best thing of them? & Free text response \\
\hline What is the worst thing of them? & Free text response \\
\hline Please evaluate gamification method & $1-10$ \\
\hline What do you improve in them? & Free text response \\
\hline Evaluate the use of TIC resources & $1-10$ \\
\hline Please indicate the best one & $\begin{array}{l}\text { Multiple option choice: Kahoot, } \\
\text { Plickers, Socrative, Quizziz, Other }\end{array}$ \\
\hline Evaluate the practical seminars & $1-10$ \\
\hline What was the best one? & $\begin{array}{l}\text { Multiple option choice: Escape room, } \\
\text { classical lab activities, Break Out Edu }\end{array}$ \\
\hline What was the worst one? & Multiple option choice \\
\hline What is the best thing inside the course? & Free text response \\
\hline And the worst thing? & Free text response \\
\hline Do you think you have learnt something about Science? & Yes/No/Maybe \\
\hline $\begin{array}{l}\text { Do you think you have learnt something different from Science } \\
\text { (other skills, other contents ... )? }\end{array}$ & Yes/No/Maybe \\
\hline $\begin{array}{l}\text { If you answered Yes to the previous question, could you indicate } \\
\text { what did you learn? }\end{array}$ & Free text response \\
\hline Would you recommend a friend of you to attend to this course? & Yes/No/Maybe \\
\hline $\begin{array}{c}\text { Please suggest me anything you think can help me to improve my } \\
\text { teaching practice }\end{array}$ & Free text response \\
\hline Finally, how will you remember this course? & Free text response \\
\hline
\end{tabular}

\section{References}

1. Zamora-Polo, F.; Sánchez-Martín, J.; Corrales-Serrano, M.; Espejo-Antúnez, L. What do university students know about sustainable development goals? A realistic approach to the reception of this UN program amongst the youth population. Sustainability 2019, 11, 3533. [CrossRef]

2. Zamora-Polo, F.; Sánchez-Martín, J. Teaching for a better world. Sustainability and sustainable development goals in the construction of a change-maker university. Sustainability 2019, 11, 4224. [CrossRef]

3. Ríos, I.D.L.; Cazorla, A.; Díaz-Puente, J.M.; Yagüe, J.L. Project-based learning in engineering higher education: Two decades of teaching competences in real environments. Procedia Soc. Behav. Sci. 2010, 2, 1368-1378. [CrossRef]

4. Hargreaves, A. The emotions of teaching and educational change. In Extending Educational Change; Springer: Dordrecht, The Netherlands, 2005.

5. Hewitt, D.; Tarrant, S. Innovative Teaching and Learning in Primary Schools; SAGE: Thousand Oaks, CA, USA, 2015; ISBN 1473917379.

6. Harvey, E. Secondary Education: Perspectives, Global Issues and Challenges; Nova Science: New York, NY, USA, 2016; Volume 87.

7. Abad, E.; Gil, J.; Suárez, P. A game-based educational method relying on student-generated questions. Int. J. Eng. Educ. 2017, 33, 1786-1797.

8. Zamora-Polo, F.; Martínez Sánchez-Cortés, M.; Reyes-Rodríguez, A.M.; García Sanz-Calcedo, J. Developing project managers' transversal competences using building information modeling. Appl. Sci. 2019, 9, 4016. [CrossRef]

9. Yowel, C. Primary Schools Are Not a Good Place for Testing New Methodologies; El Pais: Madrid, Spain, 2017.

10. Brígido, M.; Borrachero, A.B.; Bermejo, M.L.; Mellado, V. Prospective primary teachers' self-efficacy and emotions in science teaching. Eur. J. Teach. Educ. 2012, 36, 200-217. [CrossRef] 
11. Mellado, V.; Borrachero, A.B.; Brígido, M.; Melo, L.V.; Dávila, M.A.; Cañada, F.; Conde, M.C.; Costillo, E.; Cubero, J.; Esteban, R.; et al. Emotions in science teaching|Las emociones en la enseñanza de las ciencias. Enseñanza Cienc. 2014, 32, 11-36.

12. Borrachero, A.B.; Brígido, M.; Gomez, R.; Bermejo, M.L.; Mellado, V. Emotions in prospective secondary teachers on the science learning and teaching process (Las emociones de los futuros profesores de secundaria sobre el aprendizaje y la enseñanza de las ciencias). Int. J. Dev. Educ. Psicol. 2011, 23, 521-530.

13. Sánchez-Martín, J.; Álvarez-Gragera, G.J.; Dávila-Acedo, M.A.; Mellado, V. What do K-12 students feel when dealing with technology and engineering issues? Gardner's multiple intelligence theory implications in technology lessons for motivating engineering vocations at Spanish Secondary School. Eur. J. Eng. Educ. 2017, 42, 1330-1343. [CrossRef]

14. Sánchez-Martin, J.; Alvarez-Gragera, G.J.; Davila-Acedo, M.A.; Mellado, V. Teaching technology: From knowing to feeling enhancing emotional and content acquisition performance through Gardner's multiple intelligences theory in technology and design lessons. J. Technol. Sci. Educ. 2017, 7, 58-79. [CrossRef]

15. Brígido, M.; Couso, D.; Gutiérrez, C.; Mellado, V. The emotions about teaching and learning science: A study of prospective primary teachers in three Spanish universities. J. Balt. Sci. Educ. 2013, 12, $299-311$.

16. Sánchez-Martin, J.; Cañada-Cañada, F.; Dávila-Acedo, M.A. Emotional responses to innovative science teaching methods: Acquiring emotional data in a general science teacher education class. J. Technol. Sci. Educ. 2018, 8, 346-359. [CrossRef]

17. De-Marcos, L.; Domínguez, A.; Saenz-De-Navarrete, J.; Pagés, C. An empirical study comparing gamification and social networking on e-learning. Comput. Educ. 2014, 75, 82-91. [CrossRef]

18. Sánchez-Martín, J.; Cañada-Cañada, F.; Dávila-Acedo, M.A. Just a game? Gamifying a general science class at university: Collaborative and competitive work implications. Think. Ski. Creat. 2017, 26, 51-59. [CrossRef]

19. Buckley, P.; Doyle, E. Gamification and student motivation. Interact. Learn. Environ. 2014, 24, 1162-1175. [CrossRef]

20. Koster, R. Theory of Fun for Game Design; Paraglyph Press: Scottsdale, AZ, USA, 2005; ISBN 1449363199.

21. Fried, R.L. The Passionate Teacher: A Practical Guide; Beacon Press: Boston, MA, USA, 2001; ISBN 0807031437.

22. González-Gómez, D.; Jeong, J.S.; Airado Rodríguez, D.; Cañada-Cañada, F. Performance and perception in the flipped learning model: An initial approach to evaluate the effectiveness of a new teaching methodology in a general science classroom. J. Sci. Educ. Technol. 2016, 25, 450-459. [CrossRef]

23. Jeong, J.S.; González-Gómez, D.; Cañada-Cañada, F. How does a flipped classroom course affect the affective domain toward science course? Interact. Learn. Environ. 2019, 1-13. [CrossRef]

24. Bergmann, J.; Sams, A. Flipped Learning: Gateway to Student Engagement; International Society for Technology in Education, Ed.; International Society for Technology in Education: Eugene, OR, USA, 2014; ISBN 9781564843449.

25. Fidalgo-Blanco, A.; Martinez-Nuñez, M.; Borrás-Gene, O.; Sanchez-Medina, J.J. Micro flip teaching-An innovative model to promote the active involvement of students. Comput. Human Behav. 2017, 72, 713-723. [CrossRef]

26. Medina, J.J. Brain Rules: 12 Principles for Surviving and Thriving at Work, Home, and School; Pear Press: Seattle, WA, USA, 2008.

27. Novak, G.M.; Patterson, E.T.; Gavrin, A.D.; Christian, W. Just-In-Time Teaching: Blending Active Learning with Web Technology; Prentice Hall Series in Educational Innovation; Addison-Wesley: Saddle River, NJ, USA, 1999; ISBN 0130850349.

28. Nicholson, S. Peeking behind the locked door: A survey of escape room facilities. White Pap. 2015. Available online: http//scottnicholson.com/pubs/erfacwhite.pdf (accessed on 12 December 2019).

29. Vörös, A.I.V.; Sárközi, Z. Physics escape room as an educational tool. American Institute of Physics. AIP Conf. Proc. 2017, 1916, 050002.

30. Jeong, J.S.; González-Gómez, D.; Cañada-Cañada, F. Students' perceptions and emotions toward learning in a flipped general science classroom. J. Sci. Educ. Technol. 2016, 25, 747-758. [CrossRef]

31. Dávila Acedo, M.A.; Borrachero Cortés, A.B.; Cañada-Cañada, F.; Martinez Borreguero, G.; Sánchez Martín, J. Evolution of the emotions experienced by prospective primary teachers, focused on didactics of matter and energy. Eureka Sobre Enseñanza Divulg. Cienc. 2015, 12, 550-564.

32. Patton, M.Q. Qualitative Evaluation and Research Methods, 2nd ed.; Hardcover; Sage Publications: Newbury Park, CA, USA, 1990; ISBN 0-8039-3779-2. 
33. IBM. SPSS 14.0 Developer's Guide; IBM: Chicago, IL, USA, 2005.

34. Borrego, C.; Fernández, C.; Blanes, I.; Robles, S. Room escape at class: Escape games activities to facilitate the motivation and learning in computer science. JOTSE 2017, 7, 162-171. [CrossRef]

35. Clarke, S.; Arnab, S.; Keegan, H.; Morini, L.; Wood, O. Escaped: Adapting live-action, interactive games to support higher education teaching and learning practices. In Lecture Notes in Computer Science (Including Subseries Lecture Notes in Artificial Intelligence and Lecture Notes in Bioinformatics); Springer: Cham, Switzerland, 2016.

36. Eukel, H.N.; Frenzel, J.E.; Cernusca, D. Educational gaming for pharmacy students—Design and evaluation of a diabetes-themed escape room. Am. J. Pharm. Educ. 2017, 81, 6265. [PubMed]

37. Zamora-Polo, F.; Sánchez-Martín, J.; Hipólito-Ojalvo, F.; Luque-Sendra, A. Utilización de la gamificación para el desarrollo de competencias transversales en el grado de Ingeniería Mecánica. In Proceedings of the 23rd International Congress on Project Engineering Management and Engineering, Málaga, Spain, 10-12 July 2019; AEIPRO: Málaga, Spain, 2019.

38. Zamora-Polo, F.; Luque-Sendra, A.; Sánchez-Martín, J.; Aguayo-González, F. Conceptual framework for the use of building information modeling in engineering education. Int. J. Eng. Educ. 2019, 35, 744-755.

39. Bujacz, A.; Dunne, S.; Fink, D.; Gatej, A.R.; Karlsson, E.; Ruberti, V.; Wronska, M.K. Why do we enjoy creative tasks? Results from a multigroup randomized controlled study. Think. Ski. Creat. 2016, 19, 188-197. [CrossRef]

40. Suwal, S.; Singh, V. Assessing students' sentiments towards the use of a Building Information Modelling (BIM) learning platform in a construction project management course. Eur. J. Eng. Educ. 2018, 43, 492-506. [CrossRef]

41. Jeong, J.S.; González-Gómez, D.; Cañada-Cañada, F.; Gallego-Picó, A.; Bravo, J.C. Effects of active learning methodologies on the students' emotions, self-efficacy beliefs and learning outcomes in a science distance learning course. J. Technol. Sci. Educ. 2019, 9, 217-227. [CrossRef]

42. Jeong, J.; Cañada-Cañada, F.; González-Gómez, D. The study of flipped-classroom for pre-service science teachers. Educ. Sci. 2018, 8, 163. [CrossRef]

43. González-Gómez, D.; Jeong, J.S.; Cañada-Cañada, F. Enhancing science self-efficacy and attitudes of Pre-Service Teachers (PST) through a flipped classroom learning environment. Interact. Learn. Environ. 2019, 1-12. [CrossRef]

44. Yang, Y.; Asaad, Y.; Dwivedi, Y. Examining the impact of gamification on intention of engagement and brand attitude in the marketing context. Comput. Human Behav. 2017, 73, 459-469. [CrossRef] 